\title{
O brincar de crianças com deficiência física: contribuição da terapia ocupacional
}

\section{The play of children with disabilities: occupational therapy contribution}

\author{
Brenda Antunes de Figueiredo ${ }^{1}$, Daniele da Silva Souza ${ }^{1}$, \\ Ângela Cristina Dornelas da Silva ${ }^{2}$
}

http://dx.doi.org/10.11606/issn.2238-6149.v27i1p29-35

Figueiredo BA, Souza DS, Silva ACD. O brincar de crianças com deficiência física: contribuição da terapia ocupacional. Rev Ter Ocup Univ São Paulo. 2016 jan.-abr.;27(1):29-35.

RESUMO: O estudo objetivou investigar as contribuições da Terapia Ocupacional para a promoção do brincar de crianças com deficiência física a partir da perspectiva dos pais. A pesquisa, de abordagem qualitativa, foi desenvolvida no período de outubro a novembro de 2014. As informações foram coletadas por meio de entrevista com o pai ou mãe de crianças com deficiência física. Por meio da análise de conteúdo observou-se que os pais passaram a valorizar o brincar no cotidiano das crianças após as orientações dos terapeutas ocupacionais, reconhecendo a sua importância para o desenvolvimento e evolução do tratamento da criança. Os pais perceberam que a Terapia Ocupacional criou possibilidades para o brincar da criança em casa e que isto contribuiu para uma maior interação familiar. Os resultados sugerem que mesmo quando os terapeutas orientam o brincar com objetivo de melhorar habilidades das crianças, eles contribuem para que esta ocupação faça parte do cotidiano familiar, possibilitando uma maior interação entre os entes.

DESCRITORES: Terapia ocupacional; Jogos e brinquedos; Desenvolvimento infantil; Pessoas com deficiência.
Figueiredo BA, Souza DS, Silva ACD. The play of children with disabilities: occupational therapy contribution. Rev Ter Ocup Univ São Paulo. 2016 Jan.-Apr.;27(1):29-35.

\begin{abstract}
The study aimed to investigate the contributions of occupational therapy to promote the play of children with physical disabilities from the parents' perspective. The research, qualitative approach was conducted in the period October-November 2014. Date were collected through an interview with the parent of children with physical disabilities. Through content analysis it was observed that parents began to enhance the play in the children's daily life after the guidelines Occupational Therapists, recognizing its importance to child development and the evolution of the child's treatment. Parents realized that the Occupational Therapy has created possibilities for the play of the child at home and that this has contributed to greater family interaction. The results suggest that even when therapists direct the play in order to improve children's abilities, they contribute to ensure that teaching is part of the daily family life, enabling greater interaction between the entities.
\end{abstract}

KEYWORDS: Occupational therapy; Play and playthings. Child development; Disabled persons.

Estudo desenvolvido no Programa Institucional de Voluntário em Iniciação Científica da Universidade Federal da Paraíba. O material é parte da pesquisa intitulada "Perspectivas de Mães sobre o Brincar no Cotidiano de Crianças com Deficiência Física e sobre a Contribuição da Terapia Ocupacional para o Brincar".

1. Acadêmica de Terapia Ocupacional e aluna do Programa Institucional de Voluntário em Iniciação Científica da Universidade Federal da Paraíba. Email: brendaafigueiredo@hotmail.com, daniele-s.s@hotmail.com

2. Terapeuta Ocupacional, Docente do Departamento de Terapia Ocupacional da UFPB, Doutora em Saúde Pública pela ENSP/FIOCRUZ. Email: angeladornelas@yahoo.com.br

Endereço para correspondência: Departamento de Terapia Ocupacional, CCS, UFPB, Campus I. Joao Pessoa, PB. CEP: 58.051-900 
Figueiredo BA, et al. O brincar de crianças com deficiência física. Rev Ter Ocup Univ São Paulo. 2016 jan./abr.;27(1):29-35.

\section{INTRODUÇÃO}

$\mathrm{O}$ brincar é considerado uma ocupação de fundamental importância na infância, pois permite que a criança explore o mundo e vivencie novas experiências. Também contribui na construção da personalidade e promove aprendizagem significativa para o desempenho ocupacional. Reilly ${ }^{1}$ ressalta que o brincar é fundamental para cultivar capacidades, habilidades, interesses e hábitos de competição e cooperação necessários para a competência na vida adulta.

O brincar deve estar presente no cotidiano de qualquer criança, pois sua ausência pode ocasionar incapacidades que prejudicam o desenvolvimento infanti1 ${ }^{2,3}$. Entretanto, quando a criança tem alguma deficiência sua autonomia para se engajar em uma brincadeira pode estar comprometida, tornando-se necessário que os pais tenham um maior envolvimento para favorecer o brincar da criança ${ }^{4,5}$.

Ferland ${ }^{6}$ destaca que o brincar permite que a criança com deficiência física conheça o mundo e desenvolva uma atitude positiva frente à ação e às habilidades nas diferentes esferas da vida. É necessário dar oportunidades para as crianças com deficiência física participarem das brincadeiras e interagirem com outras crianças e adultos ${ }^{7}$.

No que se refere à abordagem da Terapia Ocupacional relativa ao brincar, o terapeuta deve analisar os fatores que contribuem e os que podem comprometer o envolvimento da criança nas atividades lúdicas, a fim de planejar estratégias que facilitem o engajamento no brincar ${ }^{8}$.

Considerando as sessões de tratamento, Blanche ${ }^{9}$ aponta três utilizações do brincar na Terapia Ocupacional: como contexto para promover competência, como motivação, e como atividade espontânea e divertida. Entretanto, Ferland ${ }^{6}$ defende que o Terapeuta Ocupacional deve utilizar o brincar para favorecer o desenvolvimento da atitude lúdica da criança, pois o brincar é uma atividade espontânea e cercada de significados no universo infantil.

O Terapeuta Ocupacional facilita o brincar por meio de adaptações na tarefa e/ou nos brinquedos, por meio da sensibilização da família para a importância que o brincar tem na infância, e através das orientações para promover o brincar em todos os espaços pertinentes no cotidiano da criança. O uso de tecnologia assistiva também se constitui como ferramenta da clínica. A utilização de adaptadores para a preensão de brinquedos, o uso de softwares para computadores, adaptações de mobiliário, entre outros, favorecem o acesso de crianças com deficiência física ao brincar ${ }^{10}$.

O engajamento da família no processo terapêutico é fundamental e os profissionais devem envolver os pais, orientar e demonstrar formas de viabilizar o brincar para superar as limitações ${ }^{10,11}$. Os profissionais devem incentivar os pais a verem o filho para além da deficiência. Ao conhecer o filho não somente em suas dificuldades, mas, sobretudo em suas potencialidades, os pais tornam-se mais inclinados a fazer atividades cotidianas em conjunto e passam a perceber as reações que o filho tem às suas ações ${ }^{6}$.

O Terapeuta Ocupacional deve estimular o prazer propiciado pelo brincar combinado com a melhora da capacidade de agir, que poderá resultar em autonomia e sentimento de bem estar para a criança, ao tempo que também estimula a interação pais-filhos ${ }^{12}$.

Neste contexto, surgiu o interesse de estudar como o Terapeuta Ocupacional contribui para o brincar de crianças com deficiência física. $\mathrm{O}$ cenário do estudo foi a Clínica-escola de Terapia Ocupacional da Universidade Federal da Paraíba (UFPB). Assim, o estudo teve como objetivo investigar se Terapia Ocupacional contribui para a promoção do brincar no cotidiano da criança com deficiência física, a partir da opinião dos pais.

\section{PROCEDIMENTOS METODOLÓGICOS}

Trata-se de um estudo exploratório de abordagem qualitativa, realizado com pais de crianças com deficiência física, com idades entre 0 e 12 anos, acompanhadas pela Terapia Ocupacional na Clínica Escola de Terapia Ocupacional da Universidade Federal da Paraíba, no período de outubro a novembro de 2014.

Foram identificadas 10 crianças elegíveis para o estudo por meio de consulta aos prontuários. Em seguida, as mães ou pais que acompanhavam as crianças nas terapias foram convidados a participar da pesquisa e após a aceitação foram marcadas as entrevistas. Oito pais concordaram em participar.

As informações foram coletadas por meio de um roteiro de entrevista contendo questões abertas, baseado nas concepções de Ferland ${ }^{6}$ e Blanche ${ }^{9}$ sobre o brincar da criança com deficiência física e as contribuições da Terapia Ocupacional. O roteiro contemplou questões sociais e demográficas: escolaridade, renda familiar e informações sobre a criança (idade, tipo de deficiência). O roteiro explorou também as contribuições do terapeuta ocupacional nos seguintes aspectos: se o terapeuta orientou sobre a importância do brincar; como o terapeuta ajudou a criança a brincar; se a família passou a valorizar mais o brincar após o acompanhamento do terapeuta ocupacional. $\mathrm{O}$ roteiro também permitiu que os pais fizessem quaisquer comentários sobre o tema. 
Figueiredo BA, et al. O brincar de crianças com deficiência física. Rev Ter Ocup Univ São Paulo.2016 jan./abr.;27(1):29-35.

Todas as entrevistas tiveram duração média de 20 minutos, foram realizadas por um acadêmico de Terapia Ocupacional em sala reservada nas dependências da Clinica Escola. As entrevistas foram gravadas, transcritas e em seguida analisadas de acordo com a técnica de análise de conteúdo de Bardin ${ }^{13}$.

O estudo foi aprovado pelo Comité de Ética em Pesquisa (CEP), do Centro de Ciências da Saúde (CCS), da Universidade Federal da Paraíba (UFPB), em 22 de maio de 2014, com CAAE n ${ }^{0} 31037514.0 .0000 .5188$.

Para manter sigilo sobre a identidade dos participantes são utilizadas as letras M e P, para indicar se o entrevistado era mãe ou pai, respectivamente, seguido de números arábicos de acordo com a ordem da entrevista. Para os filhos dos participantes foi adotada a letra $\mathrm{F}$ seguida pelo número arábico correspondente ao do pai ou mãe entrevistado.

\section{RESULTADOS}

Participaram do estudo seis mães e dois pais. As Tabelas 1 e 2 trazem a caracterização dos participantes e de seus filhos.

A Tabela 1 mostra que as mães são as principais acompanhantes das crianças com deficiência física atendidas na Clínica Escola de Terapia Ocupacional da UFPB. A maior parte dos entrevistados tinha idade entre 30 e 39 anos, e possuía renda de dois ou mais salários mínimos. A maioria dos entrevistados tinha educação de nível superior.

Tabela 1 - Caracterização dos participantes (idade, escolaridade, renda)

\begin{tabular}{lcll}
\hline Participantes & Idade & Escolaridade & \multicolumn{1}{c}{ Renda } \\
\hline Mãe 1 & 21 anos & $\begin{array}{l}\text { Segundo Grau } \\
\text { completo }\end{array}$ & 1 salário mínimo \\
\hline Mãe 2 & 35 anos & $\begin{array}{l}\text { Segundo Grau } \\
\text { completo }\end{array}$ & 2 salários mínimo \\
\hline Mãe 3 & 35 anos & $\begin{array}{l}\text { Superior } \\
\text { Completo }\end{array}$ & $\begin{array}{l}\text { 2 salários mínimo } \\
\text { e meio }\end{array}$ \\
\hline Mãe 4 & 31 anos & $\begin{array}{l}\text { Superior } \\
\text { Completo }\end{array}$ & $\begin{array}{l}\text { 4 salários mínimo } \\
\text { e meio }\end{array}$ \\
\hline Mãe 5 & 32 anos & $\begin{array}{l}\text { Superior } \\
\text { Completo }\end{array}$ & 1 salário mínimo \\
\hline Mãe 6 & 44 anos & $\begin{array}{l}\text { Superior } \\
\text { Completo }\end{array}$ & 2 salários mínimo \\
\hline Pai 1 & 43 anos & $\begin{array}{l}\text { Primeiro Grau } \\
\text { Incompleto }\end{array}$ & 2 salários mínimo \\
\hline Pai 2 & 37 anos & $\begin{array}{l}\text { Superior } \\
\text { Completo }\end{array}$ & $\begin{array}{l}\text { Não definida pelo } \\
\text { entrevistado }\end{array}$ \\
\hline
\end{tabular}

Tabela 2 - Caracterização dos filhos dos participantes (idade, tipo de deficiência física, tempo de terapia ocupacional)

\begin{tabular}{llll}
\hline Crianças & Idade & $\begin{array}{l}\text { Tipo de } \\
\text { Deficiência Física }\end{array}$ & $\begin{array}{l}\text { Tempo de Terapia } \\
\text { Ocupacional }\end{array}$ \\
\hline F1 & 5 anos & $\begin{array}{l}\text { Paralisia cerebral- } \\
\text { diparesiaespástica }\end{array}$ & 2 anos \\
\hline F2 & $\begin{array}{l}4 \text { anos e } \\
11 \text { meses }\end{array}$ & $\begin{array}{l}\text { Paralisia cerebral- } \\
\text { tetraparesia }\end{array}$ & 7 meses \\
\hline F3 & $\begin{array}{l}2 \text { anos e } \\
1 \text { mês }\end{array}$ & $\begin{array}{l}\text { Paralisia braquial } \\
\text { obstétrica }\end{array}$ & 1 ano e 1 mês \\
\hline F4 & 4 anos & $\begin{array}{l}\text { Paralisia cerebral- } \\
\text { hemiparesia }\end{array}$ & 1 ano \\
\hline F5 & 6 anos & $\begin{array}{l}\text { Paralisia cerebral- } \\
\text { tetraparesia }\end{array}$ & 1 ano \\
\hline F6 & 9 anos & $\begin{array}{l}\text { Paralisia cerebral- } \\
\text { diparesia espástica }\end{array}$ & 1 ano \\
\hline F7 & 6 anos & $\begin{array}{l}\text { Paralisia cerebral- } \\
\text { tetraparesia }\end{array}$ & 1 ano e 2 meses \\
\hline F8 & 3 anos & $\begin{array}{l}\text { Acidente Vascular } \\
\text { Encefálico- } \\
\text { Hemiplegia }\end{array}$ & 2 anos e 5 meses \\
\hline
\end{tabular}

A Tabela 2 mostra que o diagnóstico mais frequente no grupo estudado é o de paralisia cerebral. As idades das crianças variaram entre 2 e 9 anos. O tempo de acompanhamento pela Terapia Ocupacional variou entre sete meses e dois anos e cinco meses, com média de um ano e dois meses.

Nas análises das entrevistas foram identificados quatro núcleos temáticos que possibilitaram compreender a percepção dos pais sobre a contribuição da Terapia Ocupacional para o brincar da criança com deficiência física.

\section{DISCUSSÃO}

\section{Importância do brincar para o desenvolvimento infantil}

Os pais, com exceção de uma mãe e um pai, relataram que os terapeutas ocupacionais abordaram o brincar durante o processo de tratamento explicando a importância para o desenvolvimento infantil.

"Conversou e me explicou que era bom para ele, para o desenvolvimento dele, para percepção dele... Sim, foi explicado sim". M2

\section{“Todas as terapeutas conversam”. M6}

Os relatos mostram que os terapeutas ocupacionais estão preocupados com o desenvolvimento lúdico das 
Figueiredo BA, et al. O brincar de crianças com deficiência física. Rev Ter Ocup Univ São Paulo. 2016 jan./abr.;27(1):29-35.

crianças, pois compartilharam informações relevantes com os pais sobre a importância do brincar no cotidiano das crianças. Barba et al. ${ }^{14}$ destaca que partilhar o "saber" com a família é indispensável quando o objetivo da intervenção é a promoção do desenvolvimento integral da criança com necessidades especiais.

\section{Contribuição do brincar para a evolução da criança no tratamento}

Os pais relataram melhoras/evolução das crianças nas habilidades cognitivas e sensoriomotoras com a implementação do brincar. Para os pais a importância do brincar está diretamente associada à melhora no desenvolvimento destas crianças.

"[...] eu achei que melhorou mais na coordenação, na atenção que ele não tinha tanta atenção e agora ele tá um pouco mais atento". M1

"Hoje vejo muita melhora, porque ele já fica sentado, já pega alguma coisa, já bota na boca, quer dizer, para mim isso já é uma grande melhora. [...]”. M5

O terapeuta ocupacional contribui para que o sujeito descubra caminhos que possibilitem o fazer, apesar da deficiência. Neste sentido, o fazer tem que ser significativo para o sujeito, e focar no brincar é dar sentido ao processo terapêutico para as crianças ${ }^{15}$. A partir do momento que as crianças com deficiência são estimuladas e se envolvem no brincar tornam-se visíveis para os pais os avanços no desenvolvimento do filho, que adquire uma atitude mais ativa diante das situações ${ }^{6}$.

\section{Contribuição da Terapia Ocupacional na promoção do brincar}

Os pais relataram que as estratégias orientadas pelos terapeutas para incentivar o brincar foram no sentido de: estimular os componentes cognitivos e motores necessários para a brincadeira, adaptar ou facilitar o uso de brinquedos e de estimular novas formas de brincar entre pais e filhos.

"Desde o dia que eu vim para cá, que elas ficam incentivando ela a brincar, porque ela sempre tem a tendência de movimentar o braço esquerdo e as meninas aqui a orientavam a brincar com o braço direito, [...], a pegar os objetos e a forma correta de pegar as coisas". M3
"Ensina a gente brincar com brinquedo, botar ele sentado para não dificultar a educação né?!...”. P1

"Antigamente eu não tinha conhecimento o que era uma terapia ocupacional, com esse pouco tempo que eu já tenho conhecimento, eu vejo que tem mil e uma coisas ao nosso redor que a gente pode interagir com o filho da gente...". M2

É possível supor que os terapeutas ocupacionais utilizam preferencialmente o brincar como contexto para promover competência e reforçam tais aspectos nas orientações dadas aos pais. Blanche ${ }^{9}$ afirma que no tratamento das crianças com paralisia cerebral, os profissionais tendem a utilizar brinquedos ou brincadeiras voltadas para trabalhar as limitações dos movimentos.

Esta tendência se evidencia nas falas que seguem:

"[...] Ela me indicou alguns brinquedos, a massinha, por exemplo, para ela ficar movimentando a mãozinha, [...] de bola para ela jogar com as duas mãos". M3

"Sim, e eu brinco junto com ela. Ela sempre me orientou para eu ficar atenta e brincar com L. usando as duas mãos, com brincadeiras que exija a concentração dela, porque ela é muito dispersa...". M4

"Sempre, sempre me passaram as maneiras de estimular os movimentos do lado necessitado. Maneiras, exemplos de como pegar o objeto, como soltar, [...], a postura do corpo para favorecer o exercicio... ”. P2

Dentre os entrevistados apenas uma mãe relatou a orientação voltada ao incentivo do brincar como objetivo principal:

“[...] Ela disse para eu deixar ele fazer o que ele gosta, do jeito dele e assim procurar a melhor maneira dele fazer". M1

Ferland $^{6}$ destaca que à medida que os familiares se preocupam em estimular o desenvolvimento podem negligenciar outras necessidades da criança. Nesse sentido, é primordial que o profissional esclareça aos pais a importância da interação focada na experimentação do prazer durante a realização de uma atividade conjunta, que não se restringe apenas a melhorar as habilidades.

Apesar da maioria das orientações fornecidas pelos profissionais estarem relacionadas à estimulação dos aspectos motores e cognitivos das crianças, pode- 
Figueiredo BA, et al. O brincar de crianças com deficiência física. Rev Ter Ocup Univ São Paulo.2016 jan./abr.;27(1):29-35.

se considerar que os Terapeutas Ocupacionais dão importância à experimentação do brincar conjunto, pois incentivam os pais a participarem das brincadeiras com os filhos. É possível verificar em todas as falas que os pais se tornaram presentes nas atividades desenvolvidas pelos filhos, compartilhando momentos de descoberta com os mesmos.

\section{Mudanças na valorização do brincar}

No que se refere às mudanças na valorização do brincar observou-se que, com exceção de uma mãe, todos os participantes mudaram a percepção que tinham do brincar, seja na importância dada ao brincar, na forma do filho brincar e/ou na participação dos pais na brincadeira.

"Com certeza, porque eu vi durante esses encontros que a brincadeira ajudava ela no desenvolvimento, onde por meio da brincadeira ela movimentava o braço que precisava sem nem perceber". Mãe 3

"Sim, porque eu vi assim, as maneiras do jeito que ele está para brincar melhor, a forma de sentar, vi o que era o melhor conforto para ele”. Mãe 1

"Mudou, porque às vezes, há tempos atrás eu colocava L. de frente ao seu DVD e ele ficava ali: ele e o DVD. Hoje é ele, eu, o pai e o DVD quando ele quer assistir". Mãe 2

"Mudou especialmente a criatividade, esse estreitamento com a criança, me ajudou a focar principalmente na criança e a área necessitada por ele e as possibilidades que existem". Pai 2

Essas mudanças de comportamento influenciam diretamente as relações afetivas. Ao serem envolvidos no processo os pais são afetados pelas mudanças que acontecem em seus filhos ${ }^{16}$, a ação da criança repercute no ambiente familiar e vice-versa.

Samea ${ }^{16}$ afirma que a criança vista pela família com passividade, a partir do momento em que revela uma expressão mais ativa, mobiliza nos pais variados sentimentos. Estes vão desde o não reconhecimento da importância de tal atitude, devido a uma escala de valores diferentes ou pela não oportunidade de acesso ao conhecimento, até a percepção da mudança e adoção de novas atitudes frente à criança.

No conjunto dos discursos observou-se que as orientações sobre o brincar conduziram a melhor interação familiar. Isto leva a refletir sobre a importância dos profissionais, em suas intervenções, considerarem a estimulação da interação pais-crianças como uma boa estratégia para alcançar êxito no processo terapêutico. Incentivar os pais a brincarem com os filhos pode ser o caminho para fortalecer a relação de afeto entre os entes.

Quanto a participante que relatou não ter mudado a percepção sobre o brincar, afirmou que sempre deu importância a esta área de ocupação na vida de sua filha:

"Não, não mudou nada, porque eu toda vida desde que ela nasceu e começou a interagir com as outras crianças eu sempre achei a mesma coisa, que era importante”. M6

Com este núcleo temático notou-se que ocorreram mudanças nas percepções dos pais sobre o brincar desde que seus filhos começaram a ser acompanhados pela Terapia Ocupacional. Tais mudanças parecem decorrer da atitude dos terapeutas em tornarem os pais partícipes do processo terapêutico, tornando-os capazes de perceberem mais facilmente as capacidades dos seus filhos. Para Givigi ${ }^{11}$ a família pode participar do processo terapêutico de diferentes formas e essa participação permite ao terapeuta a visão privilegiada sobre o lugar do sujeito na família e as possibilidades de mudança.

Por fim, todos os entrevistados atribuíram importância à Terapia Ocupacional, não somente na área de ocupação brincar, mas no tratamento geral dos seus filhos. Foi possível verificar que mesmo de maneira indireta, os profissionais responsáveis pelos atendimentos contribuíram para a melhoria na relação pais-filhos.

"Acho que a terapia ocupacional me ajudou em tudo, desde a forma como eu pegava na mão dela, a alimentação, o brincar, o fazer correto das coisas [...]... Enfim, ela vem me ajudando até hoje com essas orientações. Mãe 4

“Como eu já falei é uma melhora ele está assim né?! E eu agradeço muito a terapia ocupacional pelo que já fez por ele. Ele nem abria essa mão e hoje ele já abre”. Mãe 5

"[...] Eu acredito muito na importância da terapia ocupacional, acredito muito. Como eu disse e quero enfatizar a evolução do meu filho em especifico está totalmente associada a essa intensidade da TO. [...] Nós como pais, sempre recorremos a varias frentes de terapias: fisioterapia, psicopedagogia, entre outras, mas a TO dentre todas essas, é umas das principais. [...]". Pai 2 
Figueiredo BA, et al. O brincar de crianças com deficiência física. Rev Ter Ocup Univ São Paulo. 2016 jan./abr.;27(1):29-35.

As orientações fornecidas pelos terapeutas ocupacionais repercutiram positivamente em outras áreas da vida da criança, não só no brincar. Quando o profissional é capaz de fazer a criança descobrir o prazer da ação, e usar as forças para compensar as fraquezas, ele contribui para assegurar as crianças com deficiência física um desenvolvimento com maior autonomia, que possibilita maior bem estar no cotidiano ${ }^{6}$.

Assim, o estudo evidenciou que ao incluir o brincar na sua abordagem clínica o Terapeuta Ocupacional pode melhorar o desempenho das crianças em suas ocupações e a interação familiar.

\section{CONCLUSÕES}

O trabalho desenvolvido possibilita compreender que os pais percebem a contribuição da Terapia Ocupacional na promoção do brincar da criança com deficiência física, e que as informações/orientações dadas pelos profissionais são incorporadas no cotidiano familiar. Os pais perceberam que a intervenção voltada

\section{REFERÊNCIAS}

1. Reilly M. Play as exploratory learning. Beverly Hills, CA: Sage Publications; 1974.

2. Canadian Association of Occupational Therapists (CAOT). Occupational therapy and children's play. Can J Occup Ther. 1996;63(2):1-9. doi: 10.1177/000841749606300201.

3. Takatori M, Bomtempo E, Benetton MJ. O brincar e a criança com deficiência física: a construção inicial de uma história em Terapia Ocupacional. Cad Ter Ocup UFSCar. 2001;9(2):91-105. Disponível em: http://www. cadernosdeterapiaocupacional.ufscar.br/index.php/ cadernos/article/view/227/181.

4. Cruz DMC, Emmel MLG. O brinquedo e o brincar na estimulação da função manual de crianças pré-escolares com deficiência física. Cad Ter Ocup UFSCar. 2007;15(1):7-17. Disponível em: http://www.cadernosdeterapiaocupacional. ufscar.br/index.php/cadernos/article/view/150/106.

5. Martini G. O brincar na Clínica de Terapia Ocupacional com crianças com deficiência física: relato de um caso. Rev Ceto. 2010;12(12):27-31. Disponível em: http://www.ceto. pro.br/revistas/12/12-05.pdf.

6. Ferland F. O modelo lúdico: o brincar, a criança com deficiência física e a terapia ocupacional. $3 \mathrm{a}$ ed. São Paulo: Roca; 2006. para o brincar contribuiu para um melhor desempenho das crianças em atividades cotidianas no contexto familiar.

Apesar das orientações dadas pelos profissionais aos pais serem direcionadas para o desenvolvimento das habilidades cognitivas e motoras das crianças, elas contribuíram para melhorar o vínculo entre família e criança. Os pais mostraram-se mais atentos às necessidades dos filhos com as orientações dadas pelos terapeutas ocupacionais.

Portanto, a participação ativa dos pais no processo terapêutico é de fundamental importância para a tomada de decisão dos profissionais. Os pais conhecem os valores familiares, a rotina e interesses da criança, e podem indicar se as condutas terapêuticas estão contribuindo para o engajamento das crianças nas atividades cotidianas e na participação social.

Por fim, ressalta-se que os terapeutas ocupacionais devem compreender o brincar em sua totalidade e não apenas como contexto para promover competências, para que possam contribuir para a promoção do brincar espontâneo, tendo em vista sua importância na vida das crianças que apresentam ou não algum comprometido físico, cognitivo ou emocional.

7. Zaguini CGS, Bianchin MA, Lucato Junior RV, Chueire RHMF. Avaliação do comportamento lúdico da criança com paralisia cerebral e da percepção de seus cuidadores. Acta Fisiatr. 2011;18(4):187-91. doi 10.5935/01047795.20110004 .

8. Rezende MB. O brincar e a intervenção da terapia ocupacional. In: Drummond AF, Rezende MB. Intervenções da terapia ocupacional. Belo Horizonte: Ed. UFMG; 2008. p.27-44.

9. Blanche EI. Fazer junto com - não fazer para: a recreação e as crianças portadoras de paralisia cerebral. In: Parham LD, Fazio LS. A recreação na terapia ocupacional pediátrica. São Paulo: Santos; 2000. p.202-18.

10. 1Reis NMM, Rezende MB. Adaptações para o brincar. In: Cavalcanti A, Galvão C. Terapia ocupacional: fundamentação e prática. Rio de Janeiro: Guanabara Koogan; 2007. p.339-344.

11. 1Givigi RCN; Santos AS; Ramos GO. Um novo olhar sobre participação da família no processo terapêutico. Rev Ter Ocup Univ São Paulo. 2011;22(3):221-8. Disponível em: http://www.revistas.usp.br/rto/article/view/46389.

12. Knox SH. Tratamento Através do Lazer e da Brincadeira. In: Neistadt ME, Crepeau EB. Willard \&Spackman terapia 
Figueiredo BA, et al. O brincar de crianças com deficiência física. Rev Ter Ocup Univ São Paulo.2016 jan./abr.;27(1):29-35.

ocupacional. Rio de Janeiro: Guanabara Koogan; 2002. p.356-63.

13. Bardin L. Análise de conteúdo. 6a ed. Lisboa: Edições 70; 2011.

14. Barba PCSD; Martinez CMS; Sanches M; Fontes M. Intervenção em Terapia Ocupacional junto a uma criança com necessidades especiais. Cad Ter Ocup UFSCar. 2002;10(1):51-60. Disponível em: http://www. cadernosdeterapiaocupacional.ufscar.br/index.php/ cadernos/article/view/223.

15. Takatori M. O brincar no cotidiano da criança com deficiência física: reflexões sobre a clínica da terapia ocupacional. São Paulo: Sprint; 2003.

16. Samea M. O papel da família no processo de terapia ocupacional: uma visão crítica. In: Kudo AM, et al. Fisioterapia, fonoaudiologia e terapia ocupacional em pediatria. São Paulo: Sarvier; 1994. p.243-6.

Artigo recebido em: 06.05.15

Artigo aceito em: 16.03.16 